Affiliations:

1. Pegg Leditschke Children's Burns Centre, Children's Health Queensland, South Brisbane, Qld, Australia WORSE THAN HOT BEVERAGE SCALDS

Authors:

Dr Jordan M Lavigne ${ }^{1,2}$

Dr Bhaveshkumar Patel ${ }^{1,2}$

Dr Kellie Stockton ${ }^{3}$

Dr Craig A. McBride ${ }^{1,2}$ Trauma Research, University of Queensland, South Brisbane, Qld, Australia

3. Bond Institute of Health \& Sport, Bond University, QId, Australia
2. Centre for Children's Burns and
Background:

Starch scalds anecdotally look worse initially than beverage scalds, but do they heal worse?

Objectives:

To identify a cohort of patients with starch scalds, and compare them to a the same burns centre in order to establish any differences in presentation, management, or outcome.
METHODS

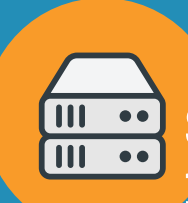

caids that occurred between 1 Jan 2013 - 30 Jun 2017 were identified within our burns centre database.

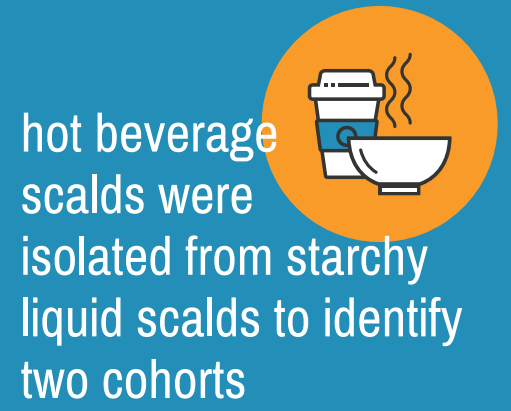

Gender, age at injury, days to presentation, cluster association,

first aid, depth of injury and outcome were able to be compared
Comparison of

outcomes to inform more accurate

prognosis to parents

RESULTS

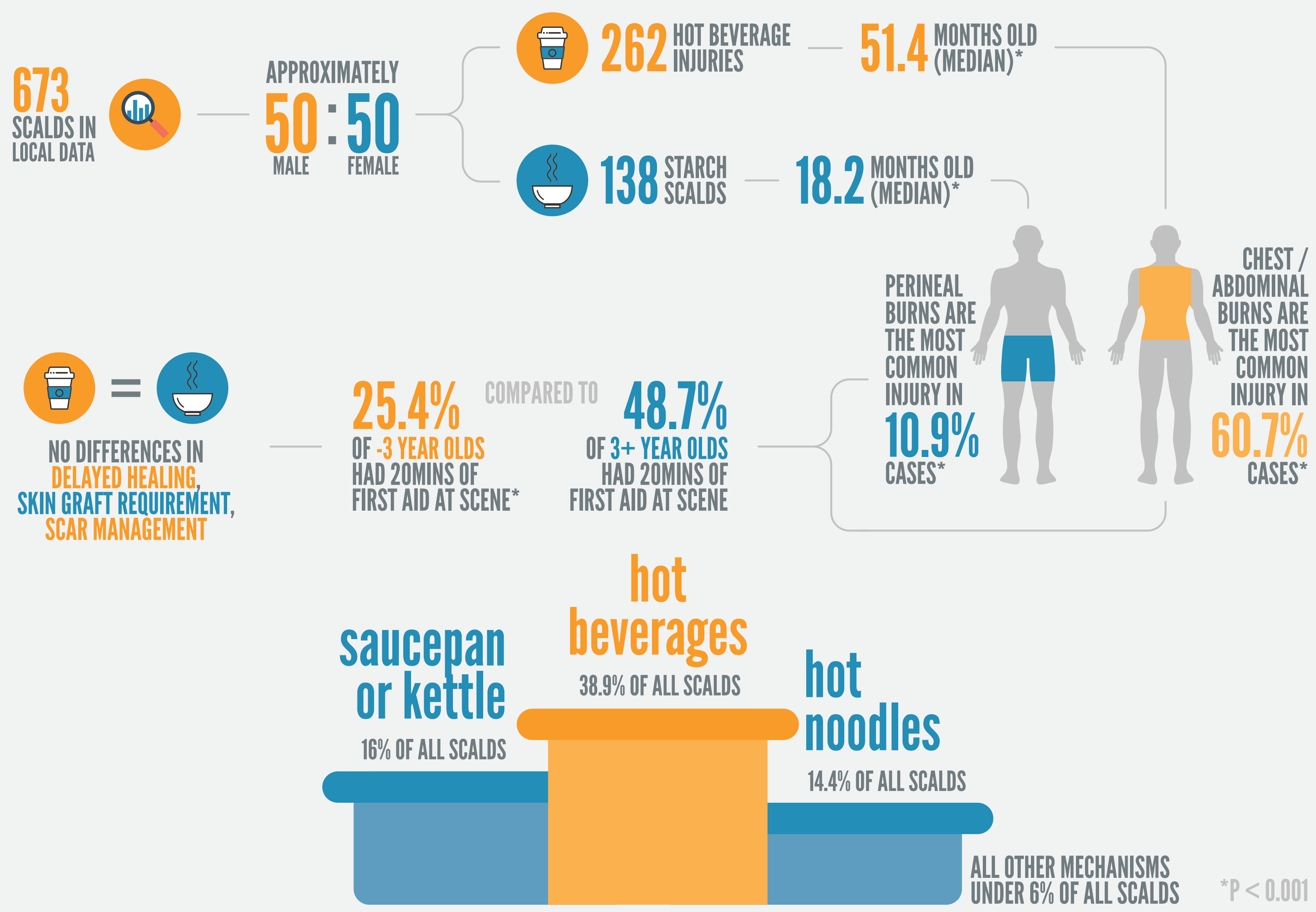

\title{
KEY FINDINGS
}

Children under 3 years of age less likely to get adequate first aid at scene.
2 Hot noodles in the lap are a common cause of scald injuries in children.
3 Hot beverages more likely to burn the chest/abdomen.
$4 \%$ risk of skin graft, $27 \%$ longer than two weeks to heal, 16\% scar management.
5 Starch burns do not heal worse than hot beverage scalds. 